\title{
Surgical Management of Glaucoma in Sturge-Weber Syndrome
}

Amit Pandey, Shantha Balekudaru*, Ronnie George, Vijaya Lingam and Manish Panday

Department of Glaucoma, Sri Jadhavbhai Nathmal Singhvi, Sankara Nethralaya, 18 College Road, Nungambakkam, Chennai-600006, Tamil Nadu, India

*Corresponding author: Shantha Balekudaru, Department of Glaucoma, Sri Jadhavbhai Nathmal Singhvi, Sankara Nethralaya, 18 College Road, Nungambakkam, Chennai-600006, Tamil Nadu, India, Tel: +914442271500; E-mail: shantha.acharya@gmail.com

Received date: September 15, 2015; Accepted date: October 31, 2015; Published date: November 10, 2015

Copyright: ( 2015 Pandey A, et al. This is an open-access article distributed under the terms of the Creative Commons Attribution License, which permits unrestricted use, distribution, and reproduction in any medium, provided the original author and source are credited.

\section{Introduction}

Sturge-Weber syndrome (SWS) or encephalo-trigeminal hemangiomatosis is a sporadic, mesodermal phakomatosis characterised by hemangiomas involving many parts of the body, particularly ocular, intracranial and facial cutaneous structures [1-3].

Glaucoma is a common feature, with an incidence of $30 \%-71 \%$ in patients with Sturge-Weber syndrome [4-6]. Many mechanisms of raised intraocular pressure have been described in the past, the most consistent being congenital trabeculodysgenesis, increased episcleral venous pressure and hypersecretion due to ciliary body angioma $[7,8]$.

An increased risk of intra and post-operative complications has been noted with glaucoma filtering procedures in these patients, predominantly due to rupture of the fragile vasculature in the choroidal hemangiomas, leading to expulsive choroidal haemorrhage or exudative choroidal detachment (CD) caused by sudden decompression during or after filtering procedures [9-13]. Prohylactic sclerotomies have been advocated, to be performed prior to ocular decompression, during filtering procedures in order to avoid these complications. The necessity of prophylactic procedures has been questioned. Eibschitz-Tsimhoni et al.[4], in a retrospective study, have reported that none of their 17 patients with SWS who underwent glaucoma filtering surgery without prophylactic posterior sclerotomy developed intraoperative suprachoroidal haemorrhage or choroidal effusion requiring therapeutic intervention [4]

The aim of our study was to evaluate the surgical outcomes in terms of intraocular pressure control, maintenance of visual acuity and complications of glaucoma surgeries, in eyes with Sturge-Weber syndrome and to evaluate risk factors leading to surgical failure.

\section{Methods}

Institutional review board and ethics committee clearance for analysis of charts was obtained before commencing the study. A retrospective chart review of all consecutive cases diagnosed with Sturge-Weber syndrome, who underwent glaucoma surgery from January 2003 to December 2013 was performed. The diagnosis of SWS was made clinically on the basis of typical ocular and systemic features. Patients without a minimum follow-up of 2 months were excluded.

The data obtained included age, gender, ocular and systemic features of SWS, visual acuity, baseline intra ocular pressure (IOP) Goldmann applanation tonometry, gonioscopy (Posner four mirror, Ocular instruments.inc. Bellevue, WA), ultra sound pachymetry (Pachette 2, DGH tech. Inc. Shermans Dale, PA), details of medical treatment for glaucoma as well as details of the glaucoma surgery. Postoperative data collected included visual acuity, IOP, number of IOP lowering medications and details of post-operative complications, including their management at post-op 1 week, 6 weeks and final follow up visit.

Glaucoma was defined as the presence of characteristic optic nerve head and/or visual field changes. Optic nerve head features included increased vertical cup: disc ratio, cup asymmetry of more than 0.2 , cup: disc ratio of $>0.7$ associated with focal or diffuse thinning of the neuro-retinal rim and/or focal or diffuse loss of retinal nerve fibre layer seen as wedge defect. Glaucomatous visual field changes were defined by Anderson's criteria as presence of at least 3 contiguous, non-edge points depressed to $\mathrm{p}<5 \%$ and atleast 1 point depressed to $\mathrm{p}<1 \%$, glaucoma hemi-field test 'outside normal limits' and pattern standard deviation depressed $\mathrm{p}<5 \%$ on standard automated perimetry.

\section{Success and failure}

Complete surgical success was defined as IOP $\geq 6$ and $<18 \mathrm{~mm} \mathrm{Hg}$ without the need of IOP lowering medications at final follow-up. If additional ocular hypotensive drugs were required to keep the IOP within this range, it was termed as qualified success. Surgical failure included eyes with post-operative IOP of less than $6 \mathrm{~mm} \mathrm{Hg}$ (defined as hypotony) or more than $18 \mathrm{~mm} \mathrm{Hg}$, need for re-surgery (excluding bleb manipulation like removal of sutures, massage or needling), loss of light perception and post-op complications such as persistent exudative choroidal detachment causing significant loss of visual acuity ( $>2$ snellen's lines) at final visit, retinal detachment (at final visit) or phthisis bulbi.

\section{Surgical procedures}

Outcomes of primary surgery only were evaluated. Trabeculectomy with Mitomycin C (MMC, $0.4 \mathrm{mg} / \mathrm{ml}, 1$ minute exposure) was the most common surgery performed $(18,66.7 \%)$, followed by trabeculotomy with trabeculectomy with MMC $(0.4 \mathrm{mg} / \mathrm{ml}, 1$ minute exposure) (4 eyes, 14.8\%). Three eyes (11.1\%) underwent trabeculotomy with trabeculectomy without use of antimetabolites. Trabeculectomy without use of antimetabolites and transcleral cyclophotocoagulation was required in 1 eye each (3.7\%).

\section{Statistical methods}

Statistical package for the social sciences (SPSS) version 14: SPSS Inc. Chicago: released 2007, was used for the analysis. The Kolmogorov-Smirnov test was applied to test for normal distribution of data. Comparison of continuous data was done with the independent-samples Student's t-test for normally distributed data. The Mann-Whitney test and the Wilcoxon signed-rank test were applied to the non-normally distributed data. Categorical data were analysed with the Chi-square test and Fisher's exact test. The Snellen's chart was used

\section{Definitions}


Page 2 of 4

to record visual acuity and the values were converted to LogMAR (logarithm of the reciprocal of the minimum angle of resolution) scale for the purpose of statistical analysis. A change of 2 Snellen's lines from the pre-operative best corrected visual acuity (BCVA) was considered a significant change. A p-value less than 0.05 was considered statistically significant in the study. Logistics regression analysis was performed to evaluate specific risk factors for developing post-op exudative choroidal detachment. The variables that were evaluated included age, sex ratio, laterality, pre-operative BCVA, baseline IOP, presence of choroidal hemangioma, pre-operative number of IOP lowering medications, and whether prophylactic sclerotomy was performed or not.

\section{Results}

Twenty seven eyes of 25 patients diagnosed with Sturge-Weber syndrome underwent glaucoma surgery in our series. The median follow- up was 20 months (range: 2-122 months). The majority of the patients were in the paediatric age group. Mean age at presentation was 10.1 years +10.3 years (range 1 month to 48 years).

Port wine staining in the distribution of the Trigeminal nerve was present in all patients $(100 \%)$. Neurological features like convulsions were seen in 5 patients (20\%) and radiological evidence (MRI/CT scan) of intracranial vascular abnormality was noted in 4 patients (16\%). Twelve patients had lid hemangioma (44.4\%) and episcleral hemangioma was present in 9 eyes (33.3\%). Twenty one eyes $(77.8 \%)$ also showed evidence of choroidal hemangioma on fundus examination.

\section{Intraocular pressure and glaucoma}

Glaucoma was bilateral in 6 patients (24\%). All 27 eyes (100\%) had open angles on gonioscopy. Initial intra ocular pressure (IOP) was $34+$ $8.2 \mathrm{~mm} \mathrm{Hg}$ ranging from 15 to $50 \mathrm{~mm} \mathrm{Hg}$. At final visit the mean IOP decreased to $15.4+7.9 \mathrm{~mm} \mathrm{Hg}(\mathrm{p}<0.001)$. The mean number of IOP lowering medications used pre operatively was $1.9+1.4$.This decreased to $0.4+0.8$ at the final visit $(\mathrm{p}<0.001)$.

\section{Visual acuity}

Seven eyes (25.9\%) showed improvement in visual acuity, seven eyes (25.9\%) showed worsening and 5 eyes (18.5\%) maintained their visual acuity during the follow-up period. Mean best corrected visual acuity (LogMAR) at initial visit was $0.7+0.8$ and at final follow-up was $0.8+$ 0.9 but this difference was not significant $(\mathrm{p}=0.905)$. Visual acuity of 4 patients in the pre-verbal group could not be measured.

\section{Surgical outcomes}

Intraoperative expulsive choroidal haemorrhage was not encountered during any surgery in our series. Out of the 27 eyes that underwent anti glaucoma surgery, complete success was achieved in 17 eyes $(62.9 \%)$ and qualified success in 1 eye $(3.7 \%)$. The reasons for surgical failure included uncontrolled IOP (4 eyes), post-operative retinal detachment (3 eyes), persistent choroidal detachment leading to significant visual acuity loss ( $>2$ Snellen's line) (2 eyes) and ocular hypotony (1 eye). The eye that had hypotony also developed choroidal detachment. One eye had both choroidal detachment and uncontrolled IOP due to secondary angle closure. Kalpan Meier survival analysis (Figure 1) showed a cumulative proportion surviving at the end of 1, 2, 3 and 4 years as $83 \%, 83 \%, 74 \%$ and $74 \%$, respectively.

\begin{tabular}{|c|c|c|}
\hline \multirow{2}{*}{ Age (Years) } & Mean+SD & $10.1+10.3$ \\
\hline & Range & $0.08-48$ \\
\hline Sex ratio & (Male:Female) & $14: 13$ \\
\hline \multirow{2}{*}{ Follow up (Months) } & Mean+SD & $37.9+37.1$ \\
\hline & Range & $2-122$ \\
\hline \multirow{2}{*}{$\begin{array}{l}\text { Duration between } \\
\text { presentation and surgery } \\
\text { (days) }\end{array}$} & Mean+SD & $132.7+282.6$ \\
\hline & Range & $1-1122$ \\
\hline \multirow{3}{*}{ Systemic findings } & Nevus Flammeus & 27 \\
\hline & Neurological features & 5 \\
\hline & Intracranial vascular abnormality & 4 \\
\hline \multirow{2}{*}{ Laterality } & Right eye & 16 \\
\hline & Left Eye & 11 \\
\hline \multirow{4}{*}{ Anterior segment } & Lid hemangioma & 12 \\
\hline & Episcleral hemangioma & 9 \\
\hline & $\begin{array}{c}\text { Tortous \& dilated episcleral } \\
\text { vessels }\end{array}$ & 13 \\
\hline & Iris hemangioma & 0 \\
\hline \multirow{2}{*}{ Pachymetry (microns) } & Mean+SD & $599.9+120.6$ \\
\hline & Range & $483-943$ \\
\hline \multirow{3}{*}{ Glaucoma } & Unilateral:bilateral & $19: 6$ \\
\hline & Open angle & 27 \\
\hline & $\begin{array}{l}\text { Visibility of blood in Sclemm's } \\
\text { canal }\end{array}$ & 21 \\
\hline Fundus & Choroidal hemangioma & 21 \\
\hline \multirow{2}{*}{$\begin{array}{l}\text { Initial visual acuity } \\
\text { (LogMAR) }\end{array}$} & Mean+SD & $0.7+0.8$ \\
\hline & Range & -0.1 to 2.5 \\
\hline \multirow{2}{*}{$\begin{array}{l}\text { Baseline intraocular } \\
\text { pressure }(\mathrm{mm} \mathrm{Hg})\end{array}$} & Mean+SD & $34+8.2$ \\
\hline & Range & $15-50$ \\
\hline \multirow{2}{*}{$\begin{array}{l}\text { Pre-op no. of glaucoma } \\
\text { medications }\end{array}$} & Mean+SD & $1.9+1.4$ \\
\hline & Range & $0-4$ \\
\hline
\end{tabular}

Table 1: Demographics and clinical features.

On performing logistics regression analysis to evaluate risk factors for surgical failure, no statistically significant difference was observed between success and failure groups in terms of age $(\mathrm{p}=0.002)$, gender $(\mathrm{p}=0.586)$, laterality $(\mathrm{p}=0.782)$, BCVA $(\mathrm{p}=0.087)$, pre-op number of AGMs $(p=0.840)$, presence of choroidal hemangioma $(p=0.326)$, and prophylactic sclerotomy $(\mathrm{p}=0.326)$. However, significantly higher baseline IOP ( $p=0.037)$ was noted in the failure group as compared to the success group. 


\section{Choroidal detachment}

Six eyes (22.2\%) developed exudative choroidal detachment (CD) after the surgery that persisted beyond 2 weeks. In the eyes that developed CD the baseline IOP was significantly higher when compared to the eyes that did not develop CD $(\mathrm{p}=0.026)$. None of the eyes in this series had undergone pre-operative medical, laser, radiation or surgical treatment for choroidal hemangioma. A greater proportion eyes that developed post-op CD had choroidal hemangioma (83.3\%) as compared to the eyes that did not develop CD (76.2\%). However, this difference was not statistically significant $(\mathrm{p}=0.146)$. Similarly, there was no significant difference between the two groups in terms of age $(p=0.805)$, gender $(p=0.918)$, visual acuity $(\mathrm{p}=0.715)$, pre-op number of AGM $(\mathrm{p}=0.939)$ or prophylactic sclerotomy $(\mathrm{p}=0.712)$.

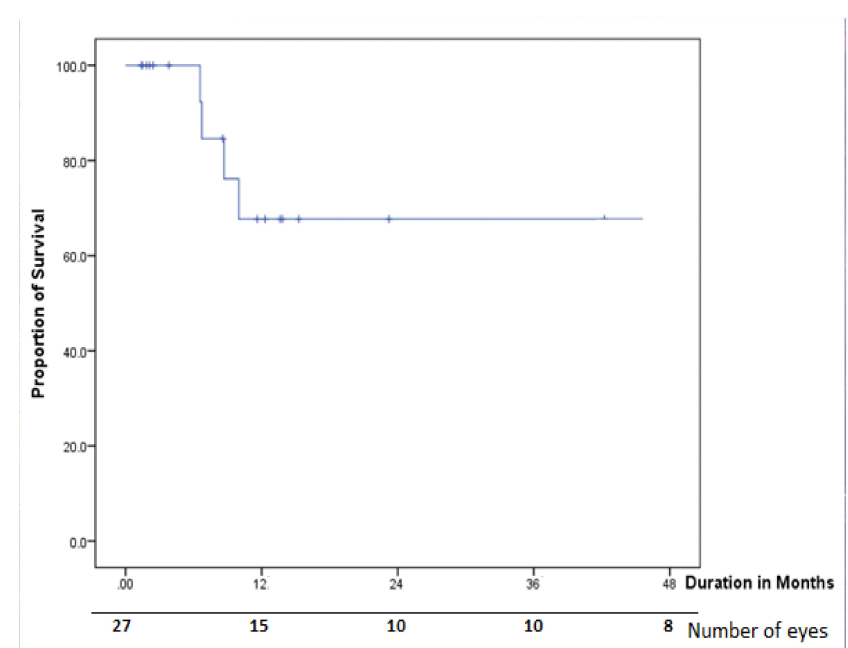

Figure 1: Kaplan-Meier survival graph for surgical success in eyes with glaucoma secondary to Sturge-Weber disease $(n=27)$. Survival was defined as no surgical failure. The number of eyes at each follow-up interval is depicted in the table.

\section{Discussion}

Glaucoma is the most common cause of visual loss in patients with Sturge-Weber syndrome [5]. Various mechanisms have been proposed in the past with trabeculo-dysgenesis being responsible in the early onset glaucoma and increased episcleral venous pressure contributing to the raised intraocular pressure later on [7].

The onset of glaucoma at birth or during infancy is a common feature [5]. This was also evident in our study with $85.2 \%$ of case belonging to the pediatric age group. Most of the glaucoma in SWS presents unilaterally, though bilateral glaucoma has also been reported $[6,13]$. In our series, $76 \%$ patients had unilateral glaucoma.

Visibility of blood in the Schlemm's canal was seen in 21 eyes (77.8\%). However, only $13(48.1 \%)$ eyes had dilated and tortuous episcleral vessels, suggesting that raised episcleral pressures may be present (and contribute to glaucoma) even without the presence of dilated episcleral vessels evidenced on slit-lamp biomicroscopic examination. A study by Shiau T, et al. showed 3 eyes (60\%) had increased episcleral venous pressure without increase in intraocular pressure or dilated episcleral vessels [5]. Their study also had 2 eyes (66\%) with glaucoma and increased episcleral venous pressure but no dialted episcleral vessels. Hence, gonioscopy should be performed in all cases of childhood glaucoma as it might be crucial in determining the mechanism of raised IOP particularly in cases where other features of SWS like facial hemangiomas are subtle or absent.

Trabeculectomy was the most common surgery performed $(n=19$, $70.4 \%)$ followed by combined trabeculotomy with trabeculectomy (25.9\%). Phelps proposed that as the site of maximum resistance to the aqueous outflow in eyes with hemangiomas would be distal to the trabecular meshwork; angle surgeries like goniotomy or trabeculectomy alone would not be enough to lower the IOP [8]. Surgical success in childhood glaucoma is quite variable and varies with the type of surgery and associated anterior segment abnormalities. Success rates reported in the literature were lower in patients with developmental glaucoma associated with syndromes such as aniridia and SWS.16 Our series had an overall success rate of $66.7 \%$. This was comparable with previous studies by Agarwal $\mathrm{HC}$ et al. (61.1\%) [16]. Combined trabeculotomy with trabeculectomy (85.7\%) had a better success rate than trabeculectomy alone (63.2\%) in our series.

On performing a logistic regression to analyse the risk factors for surgical failure and development of post-operative exudative choroidal detachment, baseline IOP was found to be a statistically significant risk factor for both surgical failure and development of choroidal detachment. This indicates that sudden decompression of the eye could be a major factor leading to the development of choroidal detachment and failure of filtering procedures.

There are very few reports of intraoperative expulsive choroidal haemorrhage in eyes with SWS undergoing glaucoma surgery [9]. None of the eyes in our series developed choroidal haemorrhage, although choroidal hemangioma was present in 21 eyes $(77.8 \%)$ including 3 eyes in which prophylactic sclerotomy was not done. Eibschitz-Tsimhoni, et al. also demonstrated that none of their 17 eyes with SWS or Klippel-Trenaunay Weber syndrome developed supra choroidal haemorrhage inspite of no pre/intra-op prophylactic measures (like sclerotomy) being undertaken [14,15]. They also debated the relevance of posterior sclerotomy in preventing post-op exudative choroidal detachmental though 6 patients developed CD in their series. None of them required any therapeutic intervention. Another study of 19 eyes reported an incidence of post-operative CD in $16.7 \%$ eyes [16]. In our series, out of the 21 eyes in which posterior sclerotomy was performed 5 (23.8\%) developed post-op CD, while out of the 6 eyes in which posterior sclerotomy was not done, 1 eye $(16.7 \%)$ developed CD. This difference was not significant statistically.

\section{Limitations}

Limitations common to retrospective analysis was also present in our study. The utility of a prophylactic sclerotomy cannot be addressed without performing a randomized controlled trial, which could be difficult due to the rarity of the disease. The sample size in our study was not adequate to correctly compare the surgical outcomes and postoperative follow up in few eyes was not long enough to comment on the success of filtering procedure. However, our sample size was fairly large when considering the rarity of this disorder and the success rates of our surgical procedures compare well with those reported in the literature. 
Citation: Pandey A, Balekudaru S, George R, Lingam V, Panday M (2015) Surgical Management of Glaucoma in Sturge-Weber Syndrome. J Eye Dis Disord 1: 101.

Page 4 of 4

\section{References}

1. Schirmer R (1860) Ein fall von teleangiektasie an account oftelangiectasia. Graefes Arch Ophthalmol 7: 119-121.

2. Sturge WA (1879) A case of partial epilepsy apparently due to alesion of one of the vasomotor centres of the brain. Trans Clin Soc Land 12: 162167.

3. Griffiths PD (1996) Sturge-Weber syndrome revisited: the role of neuroradiology. Neuropediatrics, 27: 284-294.

4. Alexander GL, Norman RM (1960) The Sturge-Weber Syndrome. Bristol: John Wright and Sons.

5. Sullivan TJ, Clarke MP, Morin JD (1992) The ocular manifestations of the Sturge-Weber syndrome. J Pediatr Ophthalmol Strabismus 29: 349-356.

6. Sharan S, Swamy B, Taranath DA, Jamieson R, Yu T, et al. (2009) Portwine vascular malformations and glaucoma risk in Sturge Weber Syndrome. J AAPOS 13: 374-378.

7. Parsa CF (2008) Sturge-Weber syndrome: A unified pathophysiologic mechanism. Curr Treat Options Neurol 10: 47-54.

8. Phelps CD (1978) The pathogenesis of glaucoma in Sturge-Weber syndrome. Ophthalmology 85: 276-286.

9. Christensen GR, Records RE (1979) Glaucoma and expulsive haemorrhage mechanisms in the Sturge-Weber syndrome. Ophthalmology 86: 1360-1366.
10. Iwach AG, Hoskins HD Jr, Hetherington J Jr, Shaffer RN (1990) Analysis of surgical and medical management of glaucoma in Sturge-Weber syndrome. Ophthalmology 97: 904-909.

11. Shihab ZM, Kristan RW (1983) Recurrent intraoperative choroidal effusion in Sturge-Weber syndrome. J Pediatr Ophthalmol Strabismus 20: 250-252.

12. Bellows AR, Chylack LT, Epstein DL, Hutchinson BT (1979) Choroidal effusion during glaucoma surgery in patients with prominent episcleral vessels. Arch Ophthalmol 97: 493-497.

13. Simmons, Richard J, Krupin, Theodore, Hitchings, et al. (1992) Serous retinal detachment after glaucoma filtration surgery in Sturge-Weber syndrome. J Glaucoma 1: 58-62.

14. Shiau T, Armogan N, Yan DB, Thomson HG, Levin AV (2012) The role of episcleral venous pressure in glaucoma associated with Sturge-Weber syndrome. J AAPOS 16: 61-64.

15. Quigley HA. (1982) Childhood glaucoma: results of trabeculotomy and study of reversible cupping. Ophthalmology 89: 219-226.

16. Agarwal HC, Sandramouli S, Sihota R, Sood NN (1993) Sturge-Weber syndrome: management of glaucoma with combined trabeculotomy and trabeculectomy. Ophthalmic Surg 24:399-402. 